\title{
Healthy dietary pattern is inversely associated with non-alcoholic fatty liver disease in elderly
}

\author{
Lia Silveira Adriano ${ }^{1,2}$, Helena Alves de Carvalho Sampaio ${ }^{1}$, Soraia Pinheiro Machado Arruda ${ }^{1}$, \\ Clarissa Lima de Melo Portela ${ }^{2}$, Maria Luisa Pereira de Melo ${ }^{1}$, Antônio Augusto Ferreira Carioca ${ }^{3}$ and \\ Nadia Tavares Soares ${ }^{1 *}$ \\ ${ }^{1}$ Department of Nutrition, State University of Ceara, Av. Dr. Silas Munguba 1700, 60714-903, Fortaleza, CE, Brazil \\ ${ }^{2}$ University of Fortaleza, Av. Washington Soares 1321, 60811-905, Fortaleza, CE, Brazil \\ ${ }^{3}$ Department of Nutrition, School of Public Health, University of Sao Paulo, Av. Dr. Arnaldo 715, 01246-000, Sao Paulo, SP, \\ Brazil
}

(Submitted 2 September 2015 - Final revision received 12 February 2016 - Accepted 13 March 2016 - First published online 22 April 2016)

\begin{abstract}
The prevalence of non-alcoholic fatty liver disease (NAFLD) is rising, an increase that may be associated with changes in lifestyle such as unhealthy dietary patterns. Although advanced age is a risk factor for NAFLD, no studies reporting this association in the elderly population were found. In the present study, the association between dietary patterns and NAFLD in the elderly was assessed. A study including 229 older adults was conducted. NAFLD diagnosis was defined as individuals whose ultrasound examination disclosed hepatic steatosis at any stage, in the absence of excess intake of alcoholic beverages. Dietary patterns were obtained by principal components analysis. Mean scores and standard errors of each dietary pattern were calculated for the groups with and without NAFLD, and mean scores of the two groups were compared using the Mann-Whitney $U$ test. The prevalence ratios and $95 \%$ CI were estimated for each tertile of the dietary pattern adherence scores using Poisson multiple regression models with robust variance. A total of 103 (45\%) elderly with NAFLD and four dietary patterns were identified: traditional, regional snacks, energy dense and healthy. Mean scores for adherence to the healthy pattern in the groups with and without NAFLD differed. NAFLD was inversely associated with greater adherence to the healthy pattern and directly associated with the regional snacks, after adjustment for confounders. In conclusion, healthy dietary pattern is inversely associated with NAFLD in elderly.
\end{abstract}

Key words: Non-alcoholic fatty liver disease: Dietary patterns: Elderly population

Reports in the literature on the association of non-alcoholic fatty liver disease (NAFLD) with dietary patterns are scarce, particularly in the elderly population. NAFLD has attracted increasing attention given its high prevalence, estimated at $20-30 \%$ in Western countries and $5-18 \%$ in Asia $^{(1)}$. The disease is characterised by the accumulation of fat in hepatic cells among individuals without excessive consumption of alcohol, use of steatogenic drugs or hereditary diseases ${ }^{(2)}$. NAFLD is part of a syndrome of metabolic dysregulation and associated with central obesity, advanced age, defects in insulin and glucose metabolism, dyslipidaemia, hypertension, the metabolic syndrome and inflammation ${ }^{(3)}$.

Among the different risk factors, age is noteworthy, as at older ages there is a greater prevalence of metabolic disorders related to insulin resistance, obesity and diabetes mellitus type 2 . In addition, estimates suggest that population ageing is set to increase significantly in the coming decades ${ }^{(4)}$.
Steatohepatitis, fibrosis with evolution to cirrhosis and hepatocellular carcinoma are the most severe and concerning stages of NAFLD in elderly. Moreover, NAFLD associated with other more serious types of steatosis increases mortality from $\mathrm{CVD}^{(5)}$. The global rise in the proportion of individuals over the age of 60 years coupled with increasing rates of overweight, obesity and mortality from non-communicable chronic diseases $^{(6)}$ point to the need for studies investigating the risk factors associated with these diseases. The dietary patterns are between the modifiable factors.

Another relevant aspect is that the majority of studies investigating the relationship between diet and NAFLD have used more traditional methods of assessing consumption, exploring the effect of separate nutrients or foods. This approach has led to conflicting results that are hard to interpret owing to difficulties isolating the effects of specific nutrients on the outcome ${ }^{(7)}$.

Abbreviations: NAFLD, non-alcoholic fatty liver disease; PR, prevalence ratios.

* Corresponding author: N. T. Soares, email nadiatsoares@gmail.com 
The goal of identifying dietary patterns is more recent and overcomes this limitation because the synergistic effects of the foods and nutrients are taken into account ${ }^{(8)}$. Investigating this new approach, a systematic review article published in 2015 identified only five studies assessing the association between dietary patterns and hepatic steatosis ${ }^{(9)}$, none of which specifically examined the association between NAFLD and dietary patterns in the elderly population. Against this background, the objective of the present study was to assess the association of dietary patterns with NAFLD in an elderly population.

\section{Methods}

\section{Study population and data collection}

Data collection was performed at the Arterial Hypertension Outpatient Clinic of a public hospital in 2009. The project was submitted to the Institutional Ethics Board and was approved under protocol no. 050203/09. All participants signed a free and informed consent form. Eligibility criteria for inclusion to the study were as follows: to be treated at the clinic, aged 60 years or older, be walking normally, have no previously diagnosed liver disease and no excessive intake of alcoholic beverages.

A total of 229 older adults, comprising 171 (74.7\%) women, took part in the study. The mean age of the group was 68.7 (SD 6.4) years, averaging 71.1 (SD 6.9) years among the men and 67.9 (sD 5.9) years among the women. The group with NAFLD showed lower mean age than those without the disease $(P<0.001)$. The patients with NAFLD also presented higher mean BMI $(P<0 \cdot 001)$. The energy and macronutrient intakes were similar between groups $(P>0.05)$ (Table 1$)$.

Information was collected for identification (name, sex and age), socio-economic status (monthly family income), lifestyle factors (smoking, alcohol consumption, physical activity), health profile (medication used), anthropometrics (weight and height), liver ultrasound and 24-h dietary recall (24HR) variables.

With regard to smoking and alcohol consumption, data were collected on consumption or otherwise and on respective time, quantity and frequency of use. Smokers were defined as

Table 1. Demographic, socio-economic, anthropometric, diet and lifestyle characteristics of the participants by non-alcoholic fatty liver disease (NAFLD) status

(Mean values and standard deviations; numbers and percentages)

\begin{tabular}{|c|c|c|c|c|c|}
\hline \multirow[b]{2}{*}{ Variables } & \multicolumn{2}{|c|}{ With NAFLD $(n 103)$} & \multicolumn{2}{|c|}{ Without NAFLD $(n 126)$} & \multirow[b]{2}{*}{$P^{*}$} \\
\hline & Mean & SD & Mean & SD & \\
\hline Age (years) & $67 \cdot 0$ & $5 \cdot 0$ & $70 \cdot 1$ & $7 \cdot 0$ & $<0.001 \dagger$ \\
\hline Sex (men) & & & & \multirow[t]{3}{*}{0.120} \\
\hline$n$ & \multirow{2}{*}{\multicolumn{2}{|c|}{$\begin{array}{l}21 \\
20 \cdot 4\end{array}$}} & \multirow{2}{*}{\multicolumn{2}{|c|}{$\begin{array}{l}37 \\
29 \cdot 4\end{array}$}} & \\
\hline$\%$ & & & & & \\
\hline Family income ( $\leq 1 \mathrm{MBW})$ & \multicolumn{2}{|c|}{$20 \cdot 4$} & & \multirow[t]{3}{*}{0.445} \\
\hline$n$ & \multicolumn{2}{|c|}{30} & \multirow{2}{*}{\multicolumn{2}{|c|}{$\begin{array}{l}28 \\
22 \cdot 2\end{array}$}} & \\
\hline$\%$ & \multicolumn{2}{|c|}{$29 \cdot 1$} & & & \\
\hline Physical activity (sedentary) & \multirow{2}{*}{\multicolumn{2}{|c|}{46}} & \multirow{2}{*}{\multicolumn{2}{|c|}{49}} & 0.378 \\
\hline$n$ & & & & & \\
\hline$\%$ & \multicolumn{2}{|c|}{$44 \cdot 7$} & \multicolumn{2}{|c|}{38.9} & \\
\hline Smoking (no) & & & & & 0.747 \\
\hline $\begin{array}{l}n \\
\%\end{array}$ & \multicolumn{2}{|c|}{$\begin{array}{l}53 \\
51.5\end{array}$} & \multicolumn{2}{|c|}{$\begin{array}{l}65 \\
51.6\end{array}$} & \\
\hline $\mathrm{BMI}\left(\mathrm{kg} / \mathrm{m}^{2}\right)$ & $30 \cdot 2$ & 4.7 & $26 \cdot 4$ & $3 \cdot 8$ & $<0.001 \dagger$ \\
\hline BMI (overweight‡) & & & \multirow{2}{*}{\multicolumn{2}{|c|}{50}} & $<0.001 \dagger$ \\
\hline$n$ & \multicolumn{2}{|c|}{73} & & & \\
\hline$\%$ & \multicolumn{2}{|c|}{$70 \cdot 9$} & \multicolumn{2}{|c|}{39.7} & \\
\hline Dyslipidaemia drug use (yes) & \multirow{3}{*}{\multicolumn{2}{|c|}{$\begin{array}{l}70 \\
68 \cdot 0\end{array}$}} & & & 0.559 \\
\hline$n$ & & & \multirow{2}{*}{\multicolumn{2}{|c|}{$\begin{array}{l}81 \\
64 \cdot 3\end{array}$}} & \\
\hline$\%$ & & & & & \\
\hline Hyperglycaemia drug use (yes) & & \multirow{2}{*}{\multicolumn{2}{|c|}{14}} & $<0.001 \dagger$ \\
\hline$n$ & \multirow{2}{*}{\multicolumn{2}{|c|}{$\begin{array}{l}36 \\
35 \cdot 0\end{array}$}} & & & \\
\hline$\%$ & & & & & \\
\hline Dietary intake & & & & & \\
\hline Energy (kJ/d) & 5552.5 & $1778 \cdot 6$ & $5563 \cdot 8$ & $1399 \cdot 1$ & 0.957 \\
\hline Energy $(\mathrm{kcal} / \mathrm{d})$ & $1327 \cdot 1$ & $425 \cdot 1$ & $1329 \cdot 8$ & 334.4 & 0.957 \\
\hline Protein $(\mathrm{g} / 4184 \mathrm{~kJ} / \mathrm{d}(\mathrm{g} / 1000 \mathrm{kcal} / \mathrm{d}))$ & $48 \cdot 8$ & 11.0 & $48 \cdot 3$ & 14.7 & 0.765 \\
\hline Carbohydrate $(\mathrm{g} / 4184 \mathrm{~kJ} / \mathrm{d}(\mathrm{g} / 1000 \mathrm{kcal} / \mathrm{d}))$ & 124.4 & 21.5 & 127.5 & 21.5 & 0.279 \\
\hline Dietary fibre $(\mathrm{g} / \mathrm{d})$ & $17 \cdot 1$ & $7 \cdot 4$ & $16 \cdot 8$ & $6 \cdot 6$ & 0.778 \\
\hline Lipid (g/4184 kJ/d (g/1000 kcal/d)) & $32 \cdot 7$ & $7 \cdot 8$ & $32 \cdot 1$ & 8.5 & 0.579 \\
\hline SFA $(g / 4184 \mathrm{~kJ} / \mathrm{d}(\mathrm{g} / 1000 \mathrm{kcal} / \mathrm{d}))$ & $7 \cdot 8$ & $2 \cdot 8$ & 7.9 & 4.0 & 0.799 \\
\hline MUFA $(\mathrm{g} / 4184 \mathrm{~kJ} / \mathrm{d}(\mathrm{g} / 1000 \mathrm{kcal} / \mathrm{d}))$ & $8 \cdot 6$ & 3.4 & $8 \cdot 3$ & $2 \cdot 8$ & 0.461 \\
\hline PUFA $(\mathrm{g} / 4184 \mathrm{~kJ} / \mathrm{d}(\mathrm{g} / 1000 \mathrm{kcal} / \mathrm{d}))$ & 8.9 & 4.0 & 8.2 & 4.4 & 0.218 \\
\hline Cholesterol (mg/d) & $165 \cdot 6$ & 122.5 & $154 \cdot 3$ & $78 \cdot 0$ & 0.397 \\
\hline
\end{tabular}

MBW, minimum Brazilian wage (1 MBW approximately US\$300).

* Student's $t$ test was applied to test mean differences in continuous variables and the $x^{2}$ test was applied to analyse the association between categorical variables.

† Statistically significant $(P<0.05)$

$\ddagger$ Overweight $\geq 27 \mathrm{~kg} / \mathrm{m}^{2}$. 
individuals who had smoked at least one cigarette in the last $30 \mathrm{~d}$ leading up to the study ${ }^{(10)}$ and non-smokers as those who had stopped smoking more than $30 \mathrm{~d}$ before study start. For physical activity, type of activity practised, session duration and frequency were considered. Individuals who performed moderate activity at least three times per week for at least $30 \mathrm{~min}$ were classified as practising physical $\operatorname{activity}^{(11)}$.

\section{Anthropometric measures}

Participants were weighed and measured according to the World Health Organization technique ${ }^{(12)}$. Weight was measured using calibrated digital anthropometric scales with a capacity of $180 \mathrm{~kg}$ and sensitivity to the nearest $100 \mathrm{~g}$. Height was measured using a stadiometer attached to scales, which had a capacity of $1.92 \mathrm{~m}$ and sensitivity to the nearest $0.5 \mathrm{~cm}$ (Filizola). BMI (weight $(\mathrm{kg}) /\left(\right.$ height squared $\left(\mathrm{m}^{2}\right)$ ) was calculated based on weight and height measurements, and the patients were classified according to the study by Lipschitz ${ }^{(13)}$.

\section{Liver ultrasonography and definitions of non-alcoholic fatty liver disease}

Liver ultrasound examinations were carried out using an EnVisor C ultrasound device (Philips Medical SystemsUltrasound). NAFLD diagnosis was defined according to American Gastroenterological Association recommendations ${ }^{(2)}$. A positive NAFLD diagnosis was attributed when ultrasound examinations disclosed hepatic steatosis at any stage, with or without associated biochemical changes, and in the absence of excessive intake of alcoholic beverages (abstinence or average daily alcohol intake of $<20 \mathrm{~g}$ for women and $30 \mathrm{~g}$ for men).

\section{Assessment of dietary intake}

The $24 \mathrm{HR}$ was applied by trained nutritionists on 3 nonconsecutive days, including 1 weekend day. Data on $24 \mathrm{~h}$ dietary intake were collected in the form of household measures and subsequently converted into grams for analysis of total energy consumption

\section{Dietary patterns}

Dietary patterns were obtained by first tabulating the name of the food and the quantity in grams on each recall day for each individual assessed. The elderly reported consumption of over 600 different foods.

The foods were grouped by nutritional value. Only food items consumed by at least $80 \%$ of participants, such as rice and beans, were not grouped. Foods consumed by $<5 \%$ of the sample not classified under any group were excluded, following the criteria adopted by Selem et al. ${ }^{(14)}$. Successive food groupings were tested until attaining the smallest number of groups, thus facilitating the analysis of dietary patterns.

The final analysis was performed for twenty-seven food groups. Multiple Source Method (MSM) software was used to remove the intrapersonal variance for each food group. This software, developed in 2006, uses statistical models to provide usual food intake distributions based on estimated individual intake $\mathrm{1}^{(15,16)}$ and provides estimated usual intake of each individual for each food group ${ }^{(16)}$.

Dietary patterns were derived by factor and principal component analyses (PCA), where input data were predicted from usual dietary intake in grams. The adequacy of the data was checked using the Kaiser-Meyer-Olkin (KMO) ${ }^{(17)}$ index and Bartlett's sphericity test. KMO values $\geq 0.5$ and $P \leq 0.05$ on Bartlett's sphericity test were considered acceptable $(14,18,19)$

The number of factors (patterns) retained obeyed criteria of eigenvalues $>1 \cdot 5^{(14)}$ and analysis of the scree plot graph, whereby the point at which the graph starts to become horizontal indicates the maximum number of factors to be retained $^{(17)}$. Subsequently, varimax orthogonal rotation was applied to simplify the factor matrix and facilitate interpretation of the data. These procedures are described in more detail by Hair et $a l .{ }^{(20)}$. For the interpretation of dietary patterns, food groups with rotational factor loadings $\geq 0.3$ or $\leq-0.3$ were considered. The factor loading is the coefficient of correlation between the food group and the factor ${ }^{(20)}$. Thus, factor loadings of $<|0.3|$ were not interpreted, as these did not make a significant contribution to the pattern.

The dietary patterns were named based on the overall food groups scored in each factor and on terminology adopted in previous publications. Each individual was then attributed a score for each pattern.

\section{Statistical analysis}

After defining the patterns, mean scores and standard errors of each dietary pattern were calculated for the groups with and without NAFLD. Mean scores of the two groups were then compared using the Mann-Whitney $U$ test.

Scores for each pattern were distributed in tertiles, and Poisson multiple regression models with robust variance ${ }^{(21)}$ were used to investigate the NAFLD with adherence to dietary patterns. In the statistical models, NAFLD was considered the dependent variable (dichotomous) and the dietary patterns (tertile in dummy) the independent variables of interest. Three models were built: model 1 raw; model 2 adjusted for sex, age and energy intake; and model 3 adjusted for sex, age, energy intake, BMI, smoking status, physical activity, family income and use of hypoglycaemic drugs. The model was tested by adjusting the healthy pattern for the other three patterns. Linear tendency tests were calculated using the tertile of the exposure variable as continuous. Values of $P<0.05$ were considered significant.

\section{Results}

Four dietary patterns were identified: traditional, regional snacks (Northeast of Brazil), energy dense and healthy, which together explained $29.4 \%$ of the total variance in intake, with a $\mathrm{KMO}=0.526$ and Bartlett's sphericity test $<0001$, values accepted by the literature ${ }^{(14,18,19)}$. 
The traditional pattern comprised foods commonly consumed by the Brazilian population, such as rice, beans, bread/toast, tea/coffee, sweet products/desserts/sugar (with significant negative loading for fruits, semi-skimmed and skimmed milk, whole grains and savoury bread/toast). The regional snacks pattern (Northeast of Brazil) comprised typical foods for morning and afternoon meals in the Northeast, such as tea/coffee, dairy products, cassava flour/tapioca/cuscus, butter and olive oil (with significant negative loading for rice). The energy-dense pattern included processed cold meats, beef, viscera, sweet products/desserts/sugar, soft drinks, tubers/spaghetti/pastries (with significant negative loading for white meat). The healthy pattern included fruits, vegetables/legumes, white meat, olive oil, margarine, and bread/toast (with significant negative loading for beef) (Table 2).

The number of individuals with NAFLD was 103 (45\%). Individuals without NAFLD exhibited a positive mean healthy pattern adherence score, whereas those with NAFLD had negative mean scores, with statistically significant difference between these means (Table 3).

NAFLD was inversely associated with higher adherence to the healthy pattern (prevalence ratios (PR) $0.70 ; 95 \%$ CI $\left.0.50,0.98, P_{\text {trend }}=0.037\right)$ and was directly associated with the regional snacks pattern (PR 1.42; 95\% CI 1.02, 1.92, $\left.P_{\text {trend }}=0.035\right)$ after adjustment for confounders. None of the other patterns exhibited an association with NAFLD (Table 4).
After adjusting for the other dietary patterns (traditional, regional snacks (Northeast of Brazil) and energy dense), the upper tertile of the healthy pattern remained associated (PR 0.69; $95 \%$ CI 0.48, 0.99).

\section{Discussion}

In the present study, an association between healthy dietary pattern and NAFLD was found, independently of confounding factors such as sex, age, energy intake, BMI, smoking status, physical activity, family income and use of hypoglycaemic drugs. Reports on this type of association in the literature are scarce, in contrast with cardiovascular outcomes. Before this publication, no association between a healthy dietary pattern and NAFLD in elderly had been reported in the literature.

In healthy adults, there is strong and consistent evidence that greater adherence to dietary patterns high in fruits, vegetables, whole grains, nuts, legumes, unsaturated oils, dairy products, poultry and fish, yet low in meat (red and processed) and sugarand fat-rich dairy products, is associated with a lower risk of CVD including CHD and stroke ${ }^{(22)}$.

It is important to point out that NAFLD has been previously associated with central obesity, advanced age, deficits in insulin and glucose metabolism, dyslipidaemia, hypertension, the metabolic syndrome and inflammation ${ }^{(3)}$. Thus, a healthy

Table 2. Factor loadings for four dietary patterns of elderly, derived by principal component analysis

\begin{tabular}{|c|c|c|c|c|}
\hline \multirow[b]{2}{*}{ Food items } & \multicolumn{4}{|c|}{ Dietary pattern } \\
\hline & Traditional* $^{*}$ & Regional snacks (Northeast of Brazil)† & Energy denseł & Healthy§ \\
\hline Fruit & $-0.504 \|$ & -0.011 & 0.145 & $0.322 \|$ \\
\hline Greens and vegetables & -0.130 & 0.209 & -0.005 & $0.545 \|$ \\
\hline Tubers, spaghetti, pastries & 0.257 & -0.097 & $0.462 \|$ & 0.276 \\
\hline Rice & $0.487 \|$ & $-0.307 \|$ & -0.014 & 0.174 \\
\hline Whole milk & 0.241 & 0.040 & 0.230 & -0.021 \\
\hline Beans & $0.485 \|$ & -0.136 & 0.078 & 0.019 \\
\hline Olive oil & -0.043 & $0.459 \|$ & -0.092 & $0.346 \|$ \\
\hline Butter & 0.171 & $0.676 \|$ & 0.221 & 0.001 \\
\hline Margarine & 0.078 & -0.079 & 0.066 & $0.691 \|$ \\
\hline Oil & 0.035 & -0.293 & 0.066 & -0.044 \\
\hline Beef & 0.099 & -0.106 & $0 \cdot 384 \|$ & $-0.337 \|$ \\
\hline Bread, toast, biscuits & $0.504 \|$ & -0.038 & 0.210 & $0.395 \|$ \\
\hline Eggs & 0.015 & 0.015 & 0.109 & 0.033 \\
\hline Viscera & 0.036 & 0.052 & $0.375 \|$ & -0.059 \\
\hline White meat & 0.261 & -0.146 & $-0.514 \|$ & $0.367 \|$ \\
\hline Dairy products & -0.083 & $0.751 \|$ & 0.001 & 0.035 \\
\hline Savoury snacks & $-0.360 \|$ & 0.072 & $0.363 \|$ & -0.048 \\
\hline Processed meats & -0.155 & -0.093 & $0.559 \|$ & 0.287 \\
\hline Tea, coffee & $0.446 \|$ & $0.300 \|$ & 0.076 & 0.046 \\
\hline Sweet products, desserts and sugar & $0.352 \|$ & 0.041 & $0.419 \|$ & -0.125 \\
\hline Soft drinks & 0.133 & -0.176 & $0.431 \|$ & -0.039 \\
\hline Juices & -0.053 & -0.113 & 0.268 & 0.130 \\
\hline Semi-skimmed and skimmed milk & $-0.442 \|$ & -0.130 & -0.132 & 0.169 \\
\hline Whole-grain bread, toast & $-0.448 \|$ & -0.017 & -0.151 & 0.195 \\
\hline Cassava flour, tapioca, cuscus & 0.175 & $0.546 \|$ & -0.138 & -0.190 \\
\hline Seasoned manioc flour and porridge & 0.239 & 0.074 & -0.079 & 0.071 \\
\hline Grains & -0.023 & 0.012 & -0.203 & 0.031 \\
\hline
\end{tabular}

* Percentage variance of the factor is 8.249 . † Percentage variance of the factor is 7.404 . $\neq$ Percentage variance of the factor is 7.258 . § Percentage variance of the factor is 6.468 . II Foods with loadings $\geq 0.3$ or $\leq-0.3$. 
Table 3. Means scores for dietary patterns of elderly with and without non-alcoholic fatty liver disease (NAFLD)

(Mean values with their standard errors)

\begin{tabular}{|c|c|c|c|c|c|c|c|c|c|c|c|c|}
\hline \multirow[b]{3}{*}{ Groups } & \multicolumn{12}{|c|}{ Dietary patterns } \\
\hline & \multicolumn{3}{|c|}{ Traditional } & \multicolumn{3}{|c|}{ Regional snacks (Northeast of Brazil) } & \multicolumn{3}{|c|}{ Energy dense } & \multicolumn{3}{|c|}{ Healthy } \\
\hline & Mean & $\mathrm{SE}$ & $P^{*}$ & Mean & $\mathrm{SE}$ & $P^{*}$ & Mean & SE & $P^{*}$ & Mean & $\mathrm{SE}$ & $P^{*}$ \\
\hline Without NAFLD & 0.03 & 0.09 & 0.435 & -0.00 & 0.10 & 0.470 & -0.05 & $0 \cdot 11$ & 0.933 & $0 \cdot 11$ & 0.09 & 0.024 \\
\hline With NAFLD & -0.04 & $0 \cdot 10$ & & 0.00 & 0.08 & & 0.06 & $0 \cdot 11$ & & $-0 \cdot 12$ & $0 \cdot 10$ & \\
\hline
\end{tabular}

* Mann-Whitney $U$ test.

Table 4. Association between dietary patterns and non-alcoholic fatty liver disease in elderly (Prevalence ratios (PR) and $95 \%$ confidence intervals)

\begin{tabular}{|c|c|c|c|c|c|c|}
\hline \multirow[b]{2}{*}{ Patterns } & \multicolumn{2}{|c|}{ Model 1} & \multicolumn{2}{|c|}{ Model 2} & \multicolumn{2}{|c|}{ Model 3} \\
\hline & PR & $95 \% \mathrm{Cl}$ & PR & $95 \% \mathrm{Cl}$ & PR & $95 \% \mathrm{Cl}$ \\
\hline \multicolumn{7}{|l|}{ Traditional } \\
\hline 1st tertile & \multicolumn{2}{|c|}{ Ref. } & \multicolumn{2}{|c|}{ Ref. } & \multicolumn{2}{|c|}{ Ref. } \\
\hline 2nd tertile & $1 \cdot 16$ & $0.83,164$ & $1 \cdot 20$ & $0.86,1.67$ & $1 \cdot 21$ & $0.89,1.65$ \\
\hline 3rd tertile & 0.94 & $0.65,1.37$ & 0.98 & $0.66,1.44$ & 1.05 & $0.73,1.52$ \\
\hline$P_{\text {trend }}$ & \multicolumn{2}{|c|}{0.743} & \multicolumn{2}{|c|}{0.962} & \multicolumn{2}{|c|}{0.710} \\
\hline \multicolumn{7}{|c|}{ Regional snacks (Northeast of Brazil) } \\
\hline 1st tertile & \multicolumn{2}{|c|}{ Ref. } & \multicolumn{2}{|c|}{ Ref. } & \multicolumn{2}{|c|}{ Ref. } \\
\hline 2nd tertile & 1.05 & $0.72,1.53$ & 1.00 & $0.69,1.45$ & $1 \cdot 12$ & $0.80,1.57$ \\
\hline 3rd tertile & 1.26 & $0.89,1.78$ & 1.29 & $0.91,1.83$ & 1.42 & $1.02,1.92$ \\
\hline$P_{\text {trend }}$ & \multicolumn{2}{|c|}{0.195} & \multicolumn{2}{|c|}{0.141} & \multicolumn{2}{|c|}{0.035} \\
\hline \multicolumn{7}{|l|}{ Energy dense } \\
\hline 1st tertile & \multicolumn{2}{|c|}{ Ref. } & \multicolumn{2}{|c|}{ Ref. } & \multicolumn{2}{|c|}{ Ref. } \\
\hline 2nd tertile & 1.05 & $0.74,1.48$ & 0.99 & $0.71,1.39$ & 0.99 & $0.72,1.36$ \\
\hline 3rd tertile & 0.97 & $0.68,1.39$ & 0.95 & $0.64,1.39$ & 1.05 & $0.71,1.53$ \\
\hline$P_{\text {trend }}$ & \multicolumn{2}{|c|}{0.871} & \multicolumn{2}{|c|}{0.787} & \multicolumn{2}{|c|}{0.347} \\
\hline \multicolumn{7}{|l|}{ Healthy } \\
\hline 1st tertile & \multicolumn{2}{|c|}{ Ref. } & \multicolumn{2}{|c|}{ Ref. } & \multicolumn{2}{|c|}{ Ref. } \\
\hline 2nd tertile & 0.82 & $0.59,1.13$ & 0.85 & $0.62,1.17$ & 0.94 & $0.70,1.27$ \\
\hline 3rd tertile & 0.68 & $0.48,0.98$ & 0.66 & $0.46,0.97$ & 0.70 & $0.50,0.98$ \\
\hline$P_{\text {trend }}$ & \multicolumn{2}{|c|}{0.035} & \multicolumn{2}{|c|}{0.029} & \multicolumn{2}{|c|}{0.037} \\
\hline
\end{tabular}

Model 1, crude; model 2, adjusted for sex, age and energy intake; model 3, adjusted for sex, age, energy intake, BMI, smoking status, physical activity, family income and hypoglycaemic drugs use; Ref., referent values.

dietary pattern, recognised as a protective factor for cardiovascular events and their risk factors ${ }^{(22)}$, may also play a key role in the prevention and control of NAFLD. Among 999 Chinese adults, the highest quartile of the grains-vegetables pattern (high intakes of coarse grains, tubers, vegetables, mushroom and kelp/ seaweed, cooked meat and beans) presented the lowest prevalence of NAFLD (PR 0.777; 95\% CI 0.618, 0.977, $P<0.05)^{(23)}$.

The findings of the present study corroborate the results of the few previous studies assessing dietary patterns and NAFLD, although none of the available studies specifically addressed the elderly population.

We also found associations between the regional snacks pattern with NAFLD after adjustment for confounders. This pattern was characterised by the presence of regional foods with high carbohydrates and high glycaemic load, such as cassava flour, tapioca and cuscus. Patterns with these characteristics were associated with NAFLD ${ }^{(24)}$ and with high degree of disease ${ }^{(25)}$. However, it is important to mention that the typical foods of the snack pattern are whole and minimally processed. Besides, they were not identified in patterns published by other studies.
Although the two dietary patterns (healthy and regional snacks) associated with the prevalence of NALFD have been validated by the literature, as to their effects in disease after adjustment by the four dietary patterns obtained, only the healthy pattern maintained the association (PR 0.69; 95\% CI 0:48, 0.99), strengthening its statistical power compared with other patterns.

Among 14-year-old adolescents with central obesity, the healthy pattern (characterised by consumption of whole grains, fruit, vegetables, greens and fish) obtained by factor analysis was a protective factor for the emergence of NAFLD at 17 years of age (OR 0.63; 95\% CI 0.41, 0.96, $P=0.033$ ), whereas the Western pattern (characterised by consumption of red meat, refined grains, processed meats, potato fries, whole dairy products and soft drinks) was a risk ${ }^{(26)}$, and dietary patterns were obtained by factor analysis.

Dietary patterns reflect eating habits in a more global fashion, facilitating investigations on their association with health outcomes. However, numerous subjective stages are involved as well as others with decision points of an analytical nature. The $a$ posteriori method used to derive the patterns had the advantage 
of being based on empirical data from the population under study ${ }^{(6)}$, as opposed to relying on a healthy pattern defined by other authors $^{(27)}$.

Other studies have used a priori methods of deriving dietary patterns, where a Mediterranean diet rich in olive oil was considered as the healthy pattern. In a case-control study in adults, adherence to this dietary pattern was not associated with lower risk of NAFLD but was associated with severity of the disease. A one unit increase in the MedDietScore was associated with a $36 \%$ lower likelihood of having NAFLD (OR 0.64; $95 \%$ CI $0 \cdot 45,0.92)$, after adjusting for sex and level of abdominal fat ${ }^{(28)}$.

In an intervention study involving twelve individuals over a 6-week period, the Mediterranean diet reduced hepatic steatosis, while improving peripheral insulin sensitivity, even in the absence of weight loss. The authors advocate adherence to this pattern as an inexpensive, non-toxic therapy with potential to improve NAFLD-related health status, diabetes mellitus type 2 and $\mathrm{CVD}^{(29)}$

Although no studies assessing the association of dietary patterns with NAFLD in the elderly were found, a healthy pattern in this age group has previously been associated with enhanced nutritional status, quality of life, survival ${ }^{(30)}$, lower likelihood of cognitive deficit, less risk of Alzheimer's disease $^{(31)}$ and lower mortality ${ }^{(32,33)}$. Such results underscore the potential of the method of deriving dietary patterns and their association with health outcomes, as the synergistic effects of foods and nutrients are taken into account.

There are several limitations of the present study. The dietary pattern identification method used in this study, including the subjectivity inherent to the process of grouping food items, was carried out based on the technical knowledge of the researcher.

Several decision points in the process of deriving dietary patterns by PCA also give rise to different options of collection and analysis across studies, such as the data collection method used (FFQ or 24HR), treatment of input variables (grams, portions, percentage energy), use of rotation, selection of final patterns and their naming ${ }^{(8)}$ as well as cut-off points for eigenvalues $^{(27)}$. Therefore, further studies should be conducted to better define the criteria for decisions taken throughout the methodological process

Another limitation of the present study was its cross-sectional design, as cause and effect were measured at the same time. Strengths of the study include the fact that NAFLD diagnosis took place only at the time of data collection. Thus, patients diagnosed with the disease had made no changes to their usual dietary habits in response to the condition and were not undergoing any specific treatment.

Although the NAFLD is a multifactorial disease ${ }^{(4)}$, we controlled our results (models 2 and 3 ) by the main factors associated with the outcome, such as age, sex, energy intake, BMI, smoking status, physical activity, family income and use of hypoglycaemic drugs. The associations remain even after adjustment for confounding factors, and the healthy and regional snacks patterns became increasingly important with the additional adjustments.

The methodological rigour of this study is also noteworthy, having used the MSM to remove intrapersonal variance and obtain the estimated usual intake in grams for each food group. Another advantage was the use of 24HR to estimate usual intake of food groups, thereby dispensing with the validation and calibration process required when using the FFQ.

It can be concluded that the healthy dietary pattern, characterised by consumption of a diet high in fruits, vegetables/legumes, white meat, olive oil, margarine, bread/ toast and low in red meat is inversely associated with NAFLD in older adults. Greater adherence to this dietary pattern was observed in elderly individuals without the disease.

\section{Acknowledgements}

The authors thank the participants of this study.

This research received no specific grant from any funding agency, commercial or not-for-profit sectors.

The authors' contributions are as follows: L. S. A, N. T. S.: drafting the article; L. S. A., H. A. d. C. S., S. P. M. A., A. A. F. C., N. T. S.: analysis and interpretation of data; C. L. d. M. P., H. A. d. C. S., M. L. P. d. M.: substantial contributions to conception, design and acquisition of data; A. A. F. C., N. T. S.: revising the manuscript critically for important intellectual content. All authors have approved the final draft of the manuscript.

The authors declare that there are no conflicts of interest.

\section{References}

1. Masarone M, Federico A, Abenavoli L, et al. (2014) Non alcoholic fatty liver: epidemiology and natural history. Rev Recent Clin Trials 10, 126-133.

2. Chalasani N, Younossi Z, Lavine JE, et al. (2012) The diagnosis and management of non-alcoholic fatty liver disease: practice guideline by the American Association for the Study of Liver Diseases, American College of Gastroenterology and the American Gastroenterological Association. Hepatology 55, 2005-2023.

3. Jesus RP, Nunes ALB, Magalhães LP, et al. (2011) Terapia Nutricional nas Doenças Hepáticas Crônicas e Insuficiência Hepática (Nutrition Therapy in Liver Disease and Chronic Liver Failure). São Paulo: Associação Médica Brasileira e Conselho Federal de Medicina (Sao Paulo: Brazilian Medical Association and Federal Council of Medicine).

4. Bertolotti M, Lonardo A, Mussi C, et al. (2014) Nonalcoholic fatty liver disease and aging: epidemiology to management. World J Gastroenterol 20, 14185-14204.

5. Machado MV \& Cortez-Pinto H (2014) Non-alcoholic fatty liver disease: what the clinician needs to know. World $J$ Gastroenterol 20, 12956-12980.

6. Olinto MTA (2007) Padrões alimentares: análise de componentes principais (Dietary patterns: principal component analysis). In Epidemiologia Nutricional (Nutritional Epidemiology), pp. 213-225 [G Kac, R Sichieri and DP Gigante, editors]. Rio de Janeiro: Fio Cruz/Atheneu.

7. Fan JG \& CAO HX (2013) Role of diet and nutritional management in non-alcoholic fatty liver disease. J Gastroenterol Hepatol 28, 81-87.

8. Moeller SM, Reedy J, Millen AE, et al. (2007) Dietary patterns: challenges and opportunities in dietary patterns research: an Experimental Biology workshop, April 1, 2006. J Am Diet Assoc 107, 1233-1239.

9. Koch M, Nothlings U \& Lieb W (2015) Dietary patterns and fatty liver disease. Curr Opin Lipidol 26, 30-34. 
10. Garrett BE, Dube SR, Trosclair A, et al. (2011) Cigarette smoking - United States, 1965-2008. MMWR Suppl 60, 109-113.

11. Brandrão AP, Brandão AA, Nogueira AR, et al. (2005) I diretriz Brasileira de diagnóstico e tratamento da síndrome metabólica (Brazilian guidelines for diagnosis and treatment of metabolic syndrome). Arq Bras Cardiol 84, 1-28.

12. World Health Organization (1995) Physical Status: The Use and Interpretation of Anthropometry, Report of a WHO Expert Committee. WHO Technical Reports Series no. 854. Geneva: WHO.

13. Lipschitz DA (1994) Screening for nutritional status in the elderly. Prim Care 21, 55-67.

14. Selem SS, Castro MA, César CL, et al. (2014) Associations between dietary patterns and self-reported hypertension among Brazilian adults: a cross-sectional populationbased study. J Acad Nutr Diet 114, 1216-1222.

15. Haubrock J, Nothlings N, Volatier JL, et al. (2011) Estimating usual food intake distributions by using the multiple source method in the EPIC-Potsdam calibration study. J Nutr $\mathbf{4 1}$, 914-920.

16. Hartting U, Haubrock J, Knuppel S, et al. (2011) The MSM program: web-based statistics package for estimating usual dietary intake using the multiple source method. Eur J Clin Nutr 65, Suppl. 1, S87-S91.

17. Kaiser HF (1974) An index of factor simplicity. Psychometrika 39, 31-36.

18. Matos SMA, Barreto ML, Rodrigues LC, et al. (2014) Padrões alimentares de crianças menores de cinco anos de idade residentes na capital e em municípios da Bahia, Brasil, 1996 e 1999/2000 (Dietary patterns of children under five years of age living in the State capital and other counties of Bahia State, Brazil, 1996 and 1999/2000). Cad Saúde Pública 30, 44-54.

19. Santos RO, Fisberg RM, Marchioni DM, et al. (2015) Dietary patterns for meals of Brazilian adults. Br J Nutr 114, 822-828.

20. Hair JF, Black B, Barry B, et al. (2009) Análise fatorial (Factor analysis). In Análise Multivariada de Dados (Multivariate Data Analysis), 6th ed. pp. 100-145 [JF Hair, B Black, B Barry, et al., editors]. Porto Alegre: Bookman.

21. Barros AJ \& Hirakata VN (2003) Alternatives for logistic regression in cross-sectional studies: an empirical comparison of models that directly estimate the prevalence ratio. $B M C$ Med Res Methodol 3, 21

22. US Department of Agriculture and Evidence Analysis Library Division, Center for Nutrition Policy and Promotion (2014) A Series of Systematic Reviews on the Relationship Between Dietary Patterns and Health Outcomes. Alexandria, VA: US Government Printing Office.

23. Yang CQ, Shu L, Wang S, et al. (2015) Dietary patterns modulate the risk of non-alcoholic fatty liver disease in chinese adults. Nutrients 7, 4778-4791.

24. Jia Q, Xia Y, Zhang Q, et al. (2015) Dietary patterns are associated with prevalence of fatty liver disease in adults. Eur J Clin Nutr 69, 914-921.

25. Valtueña S, Pellegrini N, Ardigò D, et al. (2006) Dietary glycemic index and liver steatosis. Am J Clin Nutr 84, 136-142.

26. Oddy WH, Herbison CE, Jacoby P, et al. (2013) The Western dietary pattern is prospectively associated with nonalcoholic fatty liver disease in adolescence. Am J Gastroenterol 108, 778-785.

27. Newby PK \& Tucker KL (2014) Empirically derived eating patterns using factor or cluster analysis: a review. Nutr Rev $\mathbf{6 2}$, $177-203$.

28. Kontogianni MD, Tileli N, Margariti A, et al. (2014) Adherence to the Mediterranean diet is associated with the severity of non-alcoholic fatty liver disease. Clin Nutr 33, 678-683.

29. Ryan MC, Itsiopoulos C, Thodis T, et al. (2013) The Mediterranean diet improves hepatic steatosis and insulin sensitivity in individuals with non-alcoholic fatty liver disease. J Hepatol 59, 138-143.

30. Anderson AL, Harris TB, Tylavsky FA, et al. (2011) Dietary patterns and survival of older adults. J Am Diet Assoc 111, 84-91.

31. Gu Y \& Scarmeas N (2011) Dietary patterns in Alzheimer's disease and cognitive aging. Curr Alzheimer Res 8, 510-519.

32. Masala G, Ceroti M, Pala V, et al. (2007) A dietary pattern rich in olive oil and raw vegetables is associated with lower mortality in Italian elderly subjects. Br J Nutr 98, 406-415.

33. Bamia C, Trichopoulos D, Ferrari P, et al. (2007) Dietary patterns and survival of older Europeans: the EPIC-elderly study (European Prospective Investigation into Cancer and Nutrition). Public Health Nutr 10, 590-598. 